\title{
JUSTIÇA SOCIAL E FORMAÇÃO DE PROFESSORES
}

\author{
MARIA INÊS MARCONDES
}

$\mathscr{P}$

reparar professores, a fim de contribuir para a diminuição das desigualdades existentes entre crianças das classes trabalhadoras, média e alta nos sistemas de escola pública de todo o mundo é uma questão crítica da educação contemporânea. A formação de professores para a justiça social (FPJS) tem assumido vários rótulos como formação anti-racista, crítica ou multicultural entre eles. A obra Justiça social: desafio para a formação de professores, organizada por Júlio Emílio Diniz-Pereira e Kenneth M. Zeichner, traz uma contribuição extremamente importante para os programas de formação de professores, ao se propor a discutir conceitualmente justiça social e apresentar experiências na formação de professores que colocaram este conceito em prática. Júlio Diniz-Pereira é professor adjunto da Faculdade de Educação da Universidade Federal de Minas Gerais (UFMG), em Belo Horizonte. É doutor em Educação, mais especificamente em Sociologia do Currículo e Formação Docente, no Departamento de Currículo e Ensino, da Universidade de Wisconsin (Madison, Estados Unidos). Zeichner é professor titular do Departamento de Currículo e Ensino da Universidade de Wisconsin (Madison, Estados Unidos), onde desenvolve trabalhos de pesquisa em ensino na área da formação docente, desenvolvimento profissional de professores e pesquisa-ação. Já organizaram,

* Resenha do livro organizado por Júlio Diniz-Pereira e Ken Zeichner, Justiça social: desafio para a formação de professores (Belo Horizonte: Autêntica, 2008. 167p. Tradução de Cristina Antunes).

** Professora do Departamento de Educação da Pontifícia Universidade Católica do Rio de Janeiro (PUC-RIO). E-mail: mim@puc-rio.br 
juntos, a coletânea $A$ pesquisa na formação e no trabalho docente (Editora Autêntica, 2002).

O livro Justiça social: desafio para a formação de professores reúne trabalhos apresentados em duas mesas-redondas sobre essa temática, em dois eventos importantes na área de Educação, nos Estados Unidos: o 570 Encontro Anual da Associação Americana das Faculdades de Formação de professores (American Association of Colleges for Teacher Education - AACTE), em fevereiro de 2005, em Washington, e o Encontro Anual da Associação Americana de Pesquisa Educacional (American Educational Research Association - AERA), em abril de 2005, na cidade de Montreal, no Canadá. Todos os capítulos do livro estão baseados em resultados de pesquisas sobre o tema, que vêm sendo realizadas há algum tempo, apresentando uma pluralidade metodológica, o que certamente é um dos aspectos positivos do livro.

O primeiro texto é da autoria de Ken Zeichner (Universidade de Wisconsin) e intitula-se "Formação de professores para a justiça social em tempo de incerteza e desigualdades crescentes”, analisando, qualitativamente, diferentes programas de formação de professores. Nele o autor se propõe a "esboçar os argumentos feitos pelos defensores dessa agenda, a variedade de práticas de formação de professores que têm sido estabelecidas dentro da ampla abrangência da justiça social" (p. 15-16). Além disso, propóe-se a apresentar sua crítica construtiva não como um observador externo, mas como "alguém que está envolvido nesse próprio trabalho todos os dias" (p. 15-16). O autor enfatiza a necessidade de aprofundar o que se pretende com esse rótulo e de saber como as várias interpretações de FPJs influenciam professores e seus alunos. Isso vai além de uma "celebração da diversidade", procurando formar professores que são determinados e "capazes de trabalhar dentro e fora de suas salas de aula, a fim de mudar as desigualdades que existem tanto no ensino, quanto na sociedade como um todo" (p. 17). Existe um reconhecimento das dimensões sociais e políticas do ensino, juntamente com suas outras dimensões, e um reconhecimento das contribuições dos professores para aumentar as oportunidades de vida de seus alunos. Há variações entre as propostas de diferentes programas que se propõem a desenvolver justiça social. Uma dimensão ao longo do qual os programas de FPJs variam é o grau em que enfatizam “interagir com culturas e esforços para construir justiça social, em oposição 
a estudar sobre culturas e trabalhos de justiça social" (p. 21). Embora todos os programas de formação de professores incluam pelo menos alguma experiência prática dirigida em escolas e, às vezes, em comunidades, os programas variam em relação à freqüência com que os futuros professores são postos em contato com alunos e alunas provenientes de diferentes perfis e à natureza dessas interações (p. 21). O autor defende a idéia de que a FPJs precisa ir além do discurso e começar a "prover ferramentas mais práticas conjuntamente com lentes conceituais". Para isso, fortes alianças devem ser formadas entre professores, administradores das escolas públicas e pais, em comunidades locais que estejam trabalhando pela mudança social, para promover justiça social dentro e na sociedade como um todo (Zeichner, 2006, p. 30).

O segundo texto, de Carol Rodgers (Universidade do Estado de Nova York), intitula-se “'A transformação da alma' - aprendendo a ensinar para a justiça social; o programa de formação de professores da Escola Putney (1950-1964)". Trata-se de um estudo histórico que procura recuperar a experiência de uma escola de formação, baseandose na análise dos arquivos da escola e em entrevistas com onze ex-alunos que vivenciaram a experiência. O programa era fundamentado nos princípios da "escolha, descoberta e aprendizagem centrada no aluno", de John Dewey, e teve como princípio básico "o compromisso de transformar o mundo". Os idealizadores da experiência procuraram, conscientemente, aplicar à formação a idéia de que os professores podiam ser formados para serem "líderes de reconstrução social" e, além de preparar professores para trabalharem em sala de aula com seus alunos, buscavam associar a formação de professores a movimentos mais amplos de mudança social. O programa da escola Putney incluía alunos morando junto a grupos inter-raciais e se reunindo com lideranças dos direitos civis nos Estados Unidos. Como parte de seus estudos, os alunos viajavam juntos, em furgões, por períodos de várias semanas, e refletiam sobre essas experiências. Essas viagens de estudo, em geral, eram dirigidas às áreas do sul dos Estados Unidos, onde aconteciam as lutas por justiça social. Através da análise da experiência da escola Putney, o autor sugere que o compromisso com questões de justiça social não advém dos requisitos do programa, mas de um lugar de autoridade interior que é a conseqüência da transformação individual. A experiência desta escola sugere que o compromisso com questôes de justiça social é 
conseqüência de encontros com questões da época, por meio do contato direto com pessoas e lugares que incorporam aquelas questões, e isso leva a um comprometimento com a reflexão interior e pública.

O terceiro texto é da autoria de Jean Moule (Universidade do Estado de Oregon) e intitula-se "Justiça social na formação docente: fardo invisível para o professor de cor". Caracteriza-se como uma pesquisa do tipo auto-estudo (do inglês self-study), no qual o pesquisador tenta compreender suas próprias experiências no sentido de que a "experiência pessoal pode fornecer discernimento e soluções para questões e problemas públicos" (Bullough \& Pinnegar, 2001, p. 15). Assim, a pesquisadora investiga o seu próprio papel na condição de acadêmica afro-americana em uma instituição de ensino e de formação de professores voltada para a perspectiva de justiça social. A coleta de dados foi realizada durante 5 anos e incluiu documentos da própria pesquisadora, como diários, reflexões, e-mails, conversas com colegas, atas de reuniōes do corpo docente, notícias dos departamentos e relatórios finais. A análise dos dados gerou padrões e temas emergentes relacionados às áreas do ensino, orientação, pesquisa e administração. A autora conclui com uma frase de Bullough e Pinnegar (2001, p. 20), ressaltando que "o objetivo da pesquisa de auto-estudo é provocar, desafiar e esclarecer, ao invés de confirmar ou determinar".

O quarto texto é da autoria de Morva McDonald (Universidade de Maryland) e intitula-se "Desafios para a implementação da justiça social na formação de professores". Trata-se de um estudo de caso qualitativo, baseado em pesquisa comparativa de dois programas de formação de professores do ensino fundamental que fazem da justiça social e da eqüidade o cerne da preparação de futuros docentes. As questóes que nortearam a pesquisa foram: como os programas de formação de professores implementam a justiça social de um modo integrado, ao longo de todo o programa (por exemplo, incluindo as disciplinas e os locais de estágio)? Como são, em tais programas, as oportunidades de aprendizagem dos futuros professores sobre justiça social?

Uma meta fundamental deste estudo foi desenvolver uma rica descrição da implementação da justiça social, na prática, por meio do contato prolongado e intensivo com esses programas, obtendo uma compreensão das experiências dos indivíduos, dos grupos e das organizaçóes, que permitisse examinar a complexidade das relaçóes e interaçóes 
dentro e por meio de diferentes contextos. Foi feita também uma pesquisa tipo survey, focando nas crenças e atitudes dos futuros professores sobre o ensino e sobre sua preparação, ao investigar as variáveis quantificáveis e os resultados. Essa metodologia mista permitiu triangular resultados e identificar conceitos complexos, cruciais para a pesquisa (p. 113).

O quinto texto, de Júlio Emílio Diniz-Pereira (Universidade Federal de Minas Gerais), "Modelos críticos de formação docente: a experiência do MST", discute o que o autor denomina de modelos críticos de formação docente, por meio de uma análise do programa de formação de educadores do MST. A pesquisa, do tipo qualitativo, baseia-se na análise de depoimentos feitos por educadoras do Movimento que participaram desse programa na década de 1990. O autor ressalta que, "independente de nossa filiação ideológica, predileção partidária e da nossa afinidade ou não com os ideais de luta do Movimento dos Trabalhadores Sem-Terra, é impossível não reconhecer que essa experiência nos deixa muitas liçóes e reflexôes para repensarmos nossos programas de preparação de profissionais da educação”. Além de participarem do programa de "formação inicial" do MST, as entrevistadas ressaltaram que as atividades mais importantes para a construção de uma identidade como educador sem-terra foram aquelas que envolveram a participação direta nas lutas do MST.

O grande valor dos textos é apresentar os pontos positivos, mas, também, as tensões que essas propostas vivenciaram e vivenciam. Portanto, trazem ao leitor uma "visão realista", evidenciando que implementar programas que visem justiça social não é tarefa fácil.

Enfim, a obra traz importantes subsídios, reflexões e análises sobre o tema, de uma forma aberta, não-dogmática. Trata-se de leitura indispensável para professores e formadores de professores no Brasil. Implementar programas que visem justiça social é tarefa árdua. A leitura atenta dessa obra pode trazer uma contribuição relevante para aqueles que se propóem a construir uma escola mais justa e, conseqüentemente, um mundo melhor. 